\title{
Initiating Culturally Responsive Teaching for Identity Construction in the Malaysian Classrooms
}

\author{
Faizah Idrus \\ Institute of Education, The International Islamic University Malaysia, Malaysia \\ Correspondence: Dr. Faizah Idrus, Dept. of Language and Literacy, Institute of Education, The International \\ Islamic University Malaysia, Jalan Gombak, 53100, Kuala Lumpur, Malaysia. E-mail: ifaizah@iium.edu.my
}

\author{
Received: December 31, 2013 Accepted: January 29, 2014 Online Published: March 6, 2014 \\ doi:10.5539/elt.v7n4p53 URL: http://dx.doi.org/10.5539/elt.v7n4p53
}

\begin{abstract}
This article presents evidence to the need for Culturally Responsive Teaching (CRT) to construct students' identity in the Malaysian classrooms. Since an important objective of education is to prepare individuals to exercise efficaciously in their environment, all students in multicultural society could benefit from exposure to CRT (Gay, 2000). In this study, a specific text (Ah Khaw Goes to Heaven) was used in the English literature classroom, which depicted conflicts in multicultural Malaya in the 1940s. A qualitative inquiry employing semi-structured, in depth interviews with 9 English language teachers in 6 schools around Kuala Lumpur were carried out. Classroom observations were conducted, and group interviews with 6 groups of students were also carried out. Thematic analysis were performed and the findings suggest that students' interpretation of CRT were influenced by an orthodox perception of their identity in the classroom and in the teaching and learning process, while teachers were more skeptical and reserved in developing CRT.
\end{abstract}

Keywords: culturally responsive teaching, identity construction, narrative inquiry, literature in English, text selections

\section{Introduction}

\subsection{Problem Statement}

Malaysia was shaken by an abhorrent racial riot mainly between Chinese and Malays in 1969. This watershed event marked the beginning of the implementation of various new policies by the ruling government to support the Malay section of the population. Singh and Mukherjee (1993, p. 90) allege that:

The outburst of racial violence in May 1969 completely changed the ethnic equation in Malaysia, bringing to the fore the urgent need for strengthening Malay political will to improve the socio-economic position of the Malays.

In a multicultural society such as Malaysia, inter-ethnic relations are always at the forefront of the news. In recent years (2005 onwards), inter ethnic conflicts have mounted on a larger scale, spreading from the capital city of Kuala Lumpur to other smaller states throughout the country. The conflicts which arose between ethnic groups in Malaysia more often than not emerged from the dissatisfaction of the non-Malays with the privileges bestowed upon the Malays by the constitution. These privileges include, but are not restricted to, the ownership of land, education scholarships in universities, greater allocation of places at the universities, business licences and many others. On the other hand, Malays questioned the loyalty of other ethnic groups to the country and felt that the Chinese and Indians had a bigger tendency to relinquish their citizenship when trouble erupted (ethnic violence) more so than the Malays did.

Whilst the issues of national integration indubitably demand the amalgamation of shared values so that all the people within a society can co-exist peacefully, the notion of shared identity is still unclear, blurred and eludes Malaysian people. It is interesting to note that there is perhaps a clearer awareness of ethnic identity than there is of national identity in the case of Malaysia (Tan, 2005). Thus, the government through many of its campaigns has, and still is trying to nurture in citizens the idea of the importance of having a shared identity accessible to all. Within this domain, the school curriculum can be the catalyst in providing the fundamental awareness and knowledge about others' cultures. 


\subsection{Significance of the Investigation}

Stereotyping in a multiethnic, multicultural society is widespread, and not uncommon. Negative stereotyping causes a lot of discomfort in society as it can damage good inter-ethnic relationships and lead to feelings of anguish and distress by those who are the target of the stereotyping. These feelings, which could be intensified in a split second, could lead to catastrophic consequences. As a society of diverse cultures, Malaysia is no stranger to stereotyping and cultural conflicts. It is therefore pertinent to look into its education system to identify which aspects of the curriculum can further be explored and manipulated as to achieve one of the aspirations in the Malaysian Education System. The new Malaysian Blueprint (2012) stresses on the need for an education system "that gives children shared values and experiences by embracing diversity" (Preliminary Report: Malaysia Education Blueprint, 2013-2015, E-9). One of, if not the most important aspects is initiating Culturally Responsive Teaching (CRT) across subjects throughout students' schooling. The English Language Arts instructional guide (2009) mentions that CRT 'involves reflecting the ways in which we interact with our students, and they interact with one another, to form positive and affirming experiences'. This act of reflection and also teacher-students relationship building should be stressed in teachers' academic endeavours but more often than not are neglected.

Within the realm of CRT Gay (2000) promotes the utilization of cultural knowledge, prior experiences, and performance styles of diverse students to make learning more appropriate and effective for them. In addition, Ladson-Billings (1994) asserts that CRT is a pedagogy that recognizes the importance of including students' cultural references in all aspects of learning. Hence, the objective of this study is to focus on the students, who generally spend more time in school than in any other places around them in that they build their identity as a person and as a person of culture based on their surroundings. Students who come from culturally diverse community as well as those who are in almost homogeneous backgrounds need to learn to function effectively in multicultural Malaysia.

The text Ah Khaw goes to Heaven is a text not prescribed in the syllabus. It was selected by the researcher for the purpose of this research as it revolved around a community with different ethnic, cultural and religious backgrounds. The use of Ah Khaw Goes to Heaven is hoped to initiate CRT in the classroom and ease and lessen cultural tensions which had amplified within the last five years (Idrus, 2012).

\subsection{Overview and Aims of the Study}

Fundamentally, this study attempts to examine the perceptions of teachers and students about whether and how narratives taught in multicultural classrooms can initiate CRT amongst teachers and also construct a sense of shared Malaysian identity among students.Thus, in doing so, a one-day workshop designed to introduce AKGTH was carried out with teachers to suggest practical ways of using the text within the context of CRT.Students and teachers were asked to reflect on the use of AKGTH for the purpose of understandingothers. The results obtained aim to be informative in pointing to the viability of facilitating shared Malaysian identity construction through selected narrative. From the analysis, Bhabha's (1994) notion of hybridity is used for locating the spaces in which CRT strategies can be initiated and developed.

\subsection{Research Questions}

This study seeks to answer three main research questions:

1) In what ways could the text Ah Khaw goes to Heaven initiate Culturally Responsive Teaching in the classrooms?

2) What are teachers and students' reactions in analysing culturally sensitive text (AKGTH) in the literature classrooms?

3) What were the strategies teachers used that could initiate the construction of shared identity?

\section{Literature Review}

\subsection{Culturally Responsive Teaching}

Gay (2002, p. 106) sees Culturally Responsive Teaching (CRT) as "using the cultural characteristics, experiences, and perspectives of ethnically diverse students as conduits for teaching them more effectively". Three key aspects outlined in CRT are namely (1) caring (inter-personal relationship), (2) effective communication (teachers' inclusive attitudes towards general and traditional values), (3) curriculum and instruction (the importance of materials in curriculum content, the necessity and effects of the multiculturalised content). It is based on the assumption that when academic knowledge and skills are situated within the lived experiences and frames of reference of students, they are more personally meaningful, have higher interest appeal, and are 
learned more easily and thoroughly. More importantly, CRT involves linking curriculum to the students' lives in authentic and meaningful ways. All these are done in the hope of bringing students of diverse background closer and to succeed in their lives outside school.

Gay further characterises how CRT builds bridges between students' home lives and school experience, bringing significant meaning to their school and social lives. CRT also acknowledges the dynamics of different cultural heritages from different ethnic groups which, by and large, would have an effect on students' attitudes and approaches to learning. According to Gay, CRT also incorporates multiple resources and instructional strategies which can be used across all content subjects in the school curriculum. CRT's characteristics are akin to the notion of the Third Space or hybrid space (Bhabha, 1994), in that teachers' willingness to provide the "space" for CRT to be applied increases the possibilities of constructing a collective identity amongst the students. Once the cultural gap is brought closer, the "other" students are no longer so aloof. Thus, a teacher who is aware of CRT would have a greater possibility of handling the dilemmas of a multicultural classroom more adeptly. It is thus imperative that teachers of multicultural classes are first and foremost knowledgeable about their students' cultural backgrounds to make progress towards the utilization of CRT strategies and thus enhancing learning. These characteristics outlined by Gay resonate the core of the investigation in that it examined teachers' classroom instructions and practices to identify whether CRT strategies are 'workable' in a highly exam oriented classroom such as Malaysia.

\subsection{Identity Construction}

Fearon (1999) who analysed the term "identity" in his study (language analysis of the meaning of identity) found it to be complicated and unclear. The notion of "sameness", the static notion of identity, is not applicable to the description of cultural identity or national identity, which is a complex, sometimes contradictory, multifaceted and not a simplistic notion. Some believe identity is relatively stable (Herrigel, 1993; Wendt, 1994) and some believe it is fluid and changing, thus it produces uncertainties (Hall, 1990; Katzenstein, 1996; Taylor, 1989).

In discussing the notion of identity, one can link the relationship between and among the different elements mentioned earlier, but it seems impossible to discuss one aspect of identity in isolation without linking it to others. This is especially true in the context of Malaysia in that people in the society come from various cultural, religious, and ethnic backgrounds; and with them come every aspect of different individual and collective identities with which they associate themselves or from which they disassociate themselves (and are associated with or disassociated from by others). This negotiation of identity is exemplified in this study through students' task engagement in the classroom using AKGTH. The concept of "other" is fundamental to understanding oneself, as people construct their identities, which define and constitute them and their groups, in contrast to others. In other words, "the other" is perceived by the group as not belonging, different in many fundamental ways and lacking some essential characteristics possessed by the group. Otherness can take many different forms such as in the dimensions of race, nationality, religion, social class, political ideology, historical events, sexual orientation or origin (Sampson, 1993).

\subsection{Hybridity}

Hybridity arises from the flow of information and the movement of people around this ever-evolving, interconnected and interactive world. To grasp the concept of hybridity, one has to look around and try to identify an item or mechanism which is genuinely pure. This search for purity is problematic as the society in which we are living today is unable to avoid the existence of a "mixture" of items, people or cultures. Luke and Luke (1999, p. 231) point out that the hybridity concept is not about a representation of things generated from different cultural value systems and practices which are disconnected, "rather cultures and hybridities are a creation of something new out of difference".

To grasp the concept of hybridity, one has to look around and try to identify an item or mechanism which is genuinely pure. This search for purity is problematic as the society in which we are living today is unable to avoid the existence of a "mixture" of items, people or cultures. Examples of this new creation in Malaysia are the "Baba and Nyonya" and the "Chetti of Malacca" communities. In the context of the hybrid urban Malaysian classroom, mixed marriages are common between different races. They are so common that there is a recognised linguistic term to describe the offspring of a Chinese person married to an Indian, which is popularly known as "Chindian" (Chinese and Indian). Although intermarriage between ethnic groups were commonly "frowned upon" in the early days of independence (1960s onwards), now it is more commonly accepted by society.

It is essential, despite the specificity of the Malaysian context, that the questions of identity and the impact of colonial intervention on the formation of multicultural nations are discussed and understood in the context of broader debates and discourses. For the purpose of this study, the concepts of CRT and hybridity are essential in 
the construction of a shared Malaysian identity amongst teachers and students in the literature classroom. To examine the research questions set out in this investigation, particularly requires locating theories that can explore and explain the relationship between the roles of teachers and students in shaping a shared Malaysian identity. In the context of this study, the concept of hybridity was embedded in the story of Ah Khaw and the lives he had to live in a community of Malays.

\section{Method}

A qualitative inquiry employing in-depth semi-structured interviews with teachers, group interviews with students and non-participant classroom observations were carried out. A concurrent triangulation design was conducted due to the nature of the data collection which was almost simultaneous for all methods.

\subsection{Sampling}

A purposeful sampling was carried out with 9 English Language teachers and their students from 6 secondary schools around Kuala Lumpur. Inqualitative inquiry, purposeful sampling seeks to understand a phenomenon from the perspective of the participants, and therefore it is important to select participants who will yield the most useful information. Semi-structured interviews (which were aimed at finding teachers and students' responses towards specific text) were carried out with all 9 teachers and group interviews with 6 groups of students consisting of 6 students each. Teachers were interviewed and observed initially before the one-day workshop. (The one day workshop was intended for the teachers to share experience of using prescribed texts and also to introduce AKGTH). However, only 7 teachers were selected as they completed the whole cycle (Observations, interviews, attending one-day workshop, second interview).

\subsection{Data Collection and Sampling Procedures}

Data collection was spread over 3 months as this was roughly the time in which English language teachers were doing short stories with their students. The data was derived from both English language teachers and their students (Form Four; Ages between 15-16 years old). 2 Malays, 2 Indians and 2 Chinese students were selected for the group interviews. Below are the tables of the number of research participants and the types of instruments used.

Table 1. The list of teachers and instruments (pre-workshop)

\begin{tabular}{lllll}
\hline & Teachers & Ethnicity & School & Instruments \\
\hline 1 & NA & Malay & TTDI & Obs \\
2 & SH & Indian & TTDI & SSI \\
3 & PL & Chinese & WM5 & SSI, Obs \\
4 & RA & Indian & WM5 & SSI, Obs \\
5 & SR & Malay & WM2 & SSI, Obs \\
6 & NR & Malay & WM2 & SSI, Obs \\
7 & AN & Indian & CS & Obs \\
8 & SL & Chinese & SJI & SSI, Obs \\
9 & FN & Malay & PU1 & SSI, Obs \\
\hline
\end{tabular}

There were 9 teachers involved (see table 1 above) prior to the one-day workshop. Semi-structured interviews (SSI) and non-participant observations (Obs) were scheduled. However, due to teachers' other commitments, 3 out of 9 teachers were unable to either be interviewed or observed. 
Table 2. The list of teachers who attended the one-day workshop

\begin{tabular}{llll}
\hline & Teachers & Ethnicity & School \\
\hline 1 & PL & Chinese & WM5 \\
2 & FN & Malay & PU1 \\
3 & RA & Indian & WM5 \\
4 & AI & Malay & CS \\
5 & AN & Indian & CS \\
6 & GR & Punjabi & WM2 \\
7 & RL & Malay & WM2 \\
\hline
\end{tabular}

From the list of 9 teachers approached before the workshop, 7 were able to attend the workshop sessions (see table 2 above).

Table 3. Total number of teachers observed (post-workshop)

\begin{tabular}{llll}
\hline & Teachers & Ethnicity & School \\
1 & PL & Chinese & WM5 \\
2. & FN & Malay & PU1 \\
3 & RA & Indian & WM5 \\
4 & AI & Malay & CS \\
5 & GR & Punjabi & WM2 \\
6 & RL & Malay & WM2 \\
\hline
\end{tabular}

From the 7 teachers who attended the workshop, only 6 were observed post workshop: 3 Malays, an Indian, a Punjabi and a Chinese teacher. The aim of the observation was to see strategies teachers employed using AKGTH which were introduced during the workshop.

Table 4. Group interviews (6 groups from 4 schools)

\begin{tabular}{lll}
\hline & Group Interviews & Descriptions \\
1 & SJI & One group \\
2 & WM5 & Two groups \\
3 & WM2 & Two groups \\
4 & PU1 & One group \\
\hline
\end{tabular}

Table 4 above refers to 6 groups from 4 schools each consisting of 6 students from different ethnic backgrounds who participated in the group interview/discussions. Each group was represented by 2 Malays, 2 Indians and 2 Chinese students.

In this study, a workshop was needed to explore teachers' awareness and also reflect on their own practices in the literature classrooms. Through the one-day workshop, teachers, perhaps will be able to take certain actions and measures to improve or refine their strategies (if need be) to maximise students' understanding of the concept of understanding others. This was to ensure that the aim of supporting the process of shared identity construction could potentially be disseminated to other teachers in their schools and the process is hoped to be continuous.

The specific objectives of the workshop were to explore how teachers can make use of short stories to:

1) Reinforce an understanding of CRT strategies in cultivating intercultural awareness amongst the students.

2) Develop the notion of shared Malaysian identity. 
3) Reduce any ethnic bias amongst students.

(refer to Appendix 2 for example of a model lesson)

The main analytical approach in this study was guided by thematic analysis. Braun \& Clarke (2006, p. 82) posit that a theme "captures something important about the data in relation to the research question, and represents some level of 'patterned' response or meaning within the data set".

Three main themes emerged from the analysis namely:

1) Strategies used

2) Teachers' dilemma

3) Consequences of highlighting stereotypes

\section{Discussion of Findings}

\subsection{The Use of AKGTH to Initiate CRT in the Construction of Shared Malaysian Identity}

AKGTH was an instrument (material) for investigation in this study. The materials used in the classroomaccording to Wright (1987) are one of the most important determinants for successfully engaging students to generate meaningful exchanges with their peers. Wright (1987, p. vii) asserts that:

Although often the social and psychological factors inherent in the roles are hidden, the process of learning a language in the classroom is underpinned by this teacher-learner relationship. It is further enriched by the part played by learning materials and the types of role implicit in the materials that are used.

Ways in which hybrid spaces (home, community and school) and hybrid practices (amalgamation of studying for examination and, for example producing playlet for class presentation) could be explored by teachers and may serve as initiators for understanding others and expansion of CRT strategies. Drawing from the findings of classroom observations, interviews with teachers, and students' group interviews, the utilisation of Malaysian short stories can create hybrid activities, roles and practices that lead to a very productive context of learning and development (Gutierrez et al., 1999).

Conflicts in the narratives used and in discussing racial/ethnic (and other) stereotyping in AKGTH can become the catalyst for expanding learning using CRT strategies. For example, from the analysis, teachers have demonstrated a variety of CRT strategiessubconsciously, which if consistently practiced and used would help in strengthening students' understanding of complex cultural practices. For example:

1) FN probed her students on the legitimacy of Mother's constant "nagging" towards Ah.

2) Khaw to embrace Islam. (FN, 164)

3) SN's discussion topic for her students about Ah Khaw's use of opium. (SN, 141)

4) RA's explanation on the use of the term "bajukurung" in the 1940s. (RA, 79)

Every Malaysian teacher should keep an open mind towards and keeping abreast with the government's effort of a more integrated society through campaigns such as Malaysia and also discussing sensitive issues such as racial "slurs" and ethnic stereotyping. The research indicated that both teachers and learners produced a variety of significant interactional patterns which could become hybrid activities to bridge the formal and informal spaces between the formal and informal syllabus and between home and school experiences. FN reflected on one of her lesson using AKGTH:

I was amazed by the maturity of these students discussing issues such as stereotyping and bias in society. They seemed unperturbed and carried on their discussions with a lot of conviction and confidence. They were alert to the current situation in certain parts of the country which implicated major ethnic groups in Malaysia. I enjoyed these discussions so much ... (FN, 221)

It goes to show that with teachers keeping open minds towards materials used, sensitive issues such as that of AKGTH can be discussed in sensible and non emotional ways. Malaysian short stories (such as AKGTH) have the potential to serve as a tool to help create a shared Malaysian identity and could become an intermediary to forge interest in understanding diverse cultures, hence working towards a more integrated society. By contrast, prescribed texts are arguably more likely to reduce the potential of constructing shared identity as they tend to be examined in specific ways (i.e. around issues such as character, plot, values) so that teachers gear text exploration towards the potential of what could be asked about in the examinations. 


\subsection{Teachers' Strategies in Executing AKGTH in the Classroom}

From the analysis, 3 main CRT strategies (following Brown, 2004) were used by teachers in using AKGTH text. They were:

1) Showing empathy and communicating effectively with students

AI. put yourself in Ah Khaw's shoes... what do you think you will do.. (In relation to Mother's demand) (FN, 120)

2) Being assertive and acting with authority

... I want to see that the groups you formed consisted of members from different ethnic background... (SN, 117)

... but we already have our own groups (SJI 97, MM)

... It's time that you get to know other people... (SN, 120)

3) Caring for students

I think it's because from we were very young, we were so used to being with the kind of...emm people we are familiar and used to...and suddenly ... it's hard to be around people from different cultural backgrounds... we need to do something about this... (PL, 32)

These strategies used by the teachers were not highlighted in the workshop and from the observed lessons, teachers had actually carried out part of CRT approaches. It can generally be said that teachers perhaps have used some of the CRT strategies in their teaching instinctively without realising them. These approaches can be developed further so that teachers are aware of their decision making in terms of achieving lessons objective at the same time closing cultural gaps between the students.

\subsection{Teachers'Dilemma in Using Culturally Sensitive Text (AKGTH) in the Literature Classrooms}

AKGTH served as an intermediary towards the formation of a shared identity amongst students in the classroom context. It was exploited by teachers involved, through the execution of 'meaningful' activities or tasks they had prepared. Meaningful tasks in this setting are activities which enhance the students' understanding of the different cultural and societal demands around them. However, it is not a straight forward process. Some students were seen confrontational towards the text. Exchanges between PN and her students about the text were noted:

... but it's wrong to force someone to embrace another religion ... (WM2, 144)

... Yes, but this happened a long time ago and many people had no idea that what they were doing was wrong... (SN, 176)

Several factors emerged during informal communication with teachers after their observed lessons relating to the constraints and problems they faced in introducing new classroom ideas and practices. The main problem reported was time constraints. This meant that since they had used one lesson for my observation, they were one lesson behind schedule. In addition, AKGTH was not the text which they were using in their normal literature lessons. So this did not actually prove effective for them in preparing students for the mid-year examinations due to take place three to four weeks after the post-workshop observations. SN commented:

Most of us are pretty much busy with completing the syllabus and getting the students ready for exams. At the end of the day, the administration and parents want to see results. So how much room is the teacher left with to get the students to think about how they can actually understand each other or to (be) involve (d) in each others' festivities? (SN, 158). Hence, to teach other texts that the ones prescribed by the courseoutline is almost impossoble by the teachers.

A great deal of teaching preparation at this time involved equipping students for the examination. An exam-oriented curriculum had been in place in the Malaysian education system since it was introduced during the colonial era by the British. Although the curriculum had been revised many times over a period of more than five decades, assessment had been an integral part not only in schools but also at tertiary level. Teachers realised that they needed to gear their students towards the exam as pressure from every corner awaits them; the Ministry of Education demands schools produce good, intelligent students; the local education department pressurises heads of schools to produce excellent results, who then order teachers to do their best to at least beat the results of neighbouring schools, not to mention being under pressure to meet the expectations of parents who want their children to do well under the guidance of the teachers.

So, how does this study fit in to the situation mentioned above, when teachers play a very limited role in decision making in the syllabus design? They are just disseminators, at least, that was what they led me to understand. 
That was why teachers said that they had to focus on finishing the syllabus and carrying out revision in time for the more important examination at the end of the term.

The quotation above sums up the dilemma in the school system in Malaysia in general and specifically for the teachers involved in this study. They hold immense responsibility to different echelons of people in the learning institution and there is an enormous pressure of accountability in delivering the prescribed syllabus in order to achieve good end results that are objectively measurable through increasing students' academic scores. Taking this into account, it is understandable that several teachers in this study were skeptical about the idea of using AKGTH apart from the prescribed ones as "covering" the syllabus must be prioritised in preparing their students for the examination. Wells (2000, p. 8) offers a different view:

Curriculum is a Means not an End: If the aim is to engage with particular students in productive activities that are personally as well as socially significant, "covering" the curriculum should not be thought of as the ultimate goal of education. Instead, the specified knowledge and skills that make up the prescribed curriculum should be seen as items in the cultural tool-kit which are to be used as means in carrying out activities of personal and social significance (Original emphasis).

However, the teachers' feedback in this study points to other directions-they generally felt that, by not "covering" the syllabus in the stipulated time, and by not engaging students with activities other than "upping" their test scores, they were taking a "pedagogical risk" and putting themselves out of step with the "effective" and the "required". As SN puts it:

Frankly speaking, I really don't know. I think I was and still I am in that system for a very long time. I have always been in a multiracial school and I have always been in an English medium school and I feel English language is a good subject to get students from other racial backgrounds to integrate. And the spirit has always been there. So when this 'hoohaa' about 1 Malaysia comes, I asked myself "Are we not?" It is there all along. So what's the fuss! It has always been there in my heart and soul. The most important task now is to gear the students towards achieving as many " $A$ "s as possible ( $S N, 94)$.

Besides teaching, most teachers hold other responsibilities from planning extra-curricular programmes to executing them, in and around the school curriculum. With this in mind, teachers have to balance teaching responsibilities and administrative accountability. It is not unusual for teachers either to decline other unrelated responsibilities, or to take on far more than they already have.

At the beginning of this research several teachers declined to take part in the study for this very reason. New ideas indubitably evoke both excitement and anxiety in different people, and teachers are no exception. The proposed idea of constructing shared Malaysian identity in the classroom drew different reactions from teachers and students in this study. Some were not sure of its viability and some were quite positive. If this idea were implemented, it could imply changes to both the teachers' "regulated" teaching schedules and their workload. They would be exposed to the "unknown", which deviates from their familiar pathways. This could also mean more teaching deadlines and might bring about the fear of being "off track". Many teachers will resist proposals for curriculum change if they fear that it will bring more work.

The classroom provides access to the "other world" when teachers have the opportunity to diversify teaching strategies by using role play, skits, socio-dramatics, case studies and many more methods with students, thus not only creating excitement in learning and boosting students' engagement with the subject, but also making manifest aspects of the hidden curriculum. As Skinner and Belmont (1993, p. 578) suggest, "Students who identify with school, classroom and lessons are more likely to be academically engaged and have positive school feelings". When teachers have a positive outlook, dynamics of the hidden curriculum can be used to the advantage of the students.

\subsection{Stereotyping and Its Consequences}

Teachers were concerned about the consequences of highlighting stereotypes in the classroom and would tend to avoid discussing issues related to ethnic stereotypes, specifically to avoid misunderstandings between their students. Students, however, were found in general more ready to discuss stereotyping as they felt that people should be aware of how it impacts on relationships with peers, especially friends from different ethnic backgrounds. They believed that some fundamental measures that Malaysians should take are to be open-minded and not judgmental, and not to start something that could provoke a sense of distrust. This implied, for them, discussing bias and prejudice as well as critically examining one's own basic assumptions, which can often be grounded in taken-for-granted stereotypes.

Although teachers showed some kind of approval of, and agreement with the process of discussion of stereotypes 
and prejudices should the need arise, they were adamant that this would have to be done in the most discreet and subtle ways. Teachers' willingness to take on this task I believe is vital as they need to negotiate the boundaries of cultural sensitivities such as ethnic stereotyping.

\subsection{AKGTH and Culturally Responsive Teaching}

The AKGTH's lessons proposed in the workshop could thereby constitute an amalgamation of students' and teacher's own experiences between home, community and school in a hybrid space. In this process, students need to decode unfamiliar terms such as "bajukurung" which is used to indicate men's clothing in AKGTH. In the present day, bajukurung is associated with ladies' clothing. Therefore, in order to decode this unfamiliarity, students need to use their home and community "funds of knowledge" (Moll et al., 1992).

The lessons also explored ways in which home discourses (with family members) could be integrated into the literature syllabus, preparing students to work with their interpretation of characters and plot and also to improve their communication and presentational skills; students need to explain the objectives of their exhibition and provide information for visitors.

Similarly, these lessons fulfilled the demand of the literature syllabus and the students' preparation for examination. In this vein, the notion of hidden curriculum (Giroux, 2001) is revealed in that students are expected to complete the proposed project in order to gain project marks, or praise for the play they produced (by the public, teachers and other students in school) and will conform to the demand of schooling process (getting good exam results in the subject).

Factors that affect the success of the construction of shared Malaysian identity can be grounded through the concept of hybrid space. The point of departure is the willingness of teachers to take 'pedagogical risks' and try out methods and materials outside the restrictions of the syllabus. From their feedback, however, teachers were certain that a wider selection of materials based on home grown products (Malaysian short stories) would enhance the meaning-making in teaching and learning literature and be highly advantageous for developing interactive skills which would transfer later to the world of work and all spheres of social interaction. This suggests the teachers would be prepared to take such risks.

The most interesting factor derived from this study appears to be the use of AKGTH in which the students' collaborative engagement with their peers and teachers were at their best. This may be because they and the principle of the hybrid space offered a relatively stress-free space, not subject to formal examination, hence allowing more informal, non-assessed comments from students, greater freedom and creativity of expression and were generally more student-centred. Thus, in order to answer to what extent Malaysian short stories were able to facilitate shared identity construction, the evidence of student-teacher, and student-student group discussions and interactions about 'the happenings' in the community, through their own experiences, suggest that they have a role to play in the classroom.

Since ethnic-related issues have been highlighted in Malaysia's recent news, it was not surprising that the students felt some common elements were needed that could bind the people together. With a common shared Malaysian identity, students and members of the broader community are able to identify themselves more closely with each other, thus creating abundant opportunities to interact, developing a strong and integrated society.

\section{Conclusion}

From the investigation, the findings can be situated in students' and teachers' home and community experiences which were characterised in a textual medium (short stories) provided opportunities for constructing a collective identity. Thus, with the amalgamation of hybrid identity of students from various cultures and beliefs, to their experience of culturally sensitive texts, which led to stereotyping, AKGTH has every potential to be used in the classroom in which CRT could be initiated. These materials could lead students in a direction supportive of teachers as well as the students in that conflicts arising from the narrative read were shared, discussed and justified through discussions, arguments and explanations with evidence. Thus, these classroom practices can be emulated in any multicultural context which has the aim of bringing students from different cultural groups closer.

Regardless of respondents' inclinations towards certain subjects or components of those subjects, it is vital that they are able to grasp and understand the messages embedded in them. Understanding these embedded values enables the students to appreciate "others" around them. It is also a life skill and has an intrinsic value for students, that of learning to use language - any language as the medium for any subject — as their own tool, but best illustrated in the literature component of English language and through Malaysian short stories, the most appropriate "homebase" for all Malaysian students in the multi-ethnic classroom. 
In a wider context, since Malaysia is generally noted as a harmonious and tolerant society, these elements need to be sustained. It can also be applied in other multi ethnic and multi cultural societies worldwide.

With more effort from teachers, students can be given more exposure to the need for a shared identity and they will consequently be more likely to work hard to ensure that Malaysia achieves the status of a fully developed country regardless of her people's ethnicity, culture or religion. Hence, to put this study into the ELT perspective, it is crucial for students and teachers of ESL to fully understand the philosophy of "unity in diversity". When they are aware of their own identity as Malaysians or any other ethno-cultural identity, working together despite religion, ethnic and cultural differences will not be as problematic. Therefore, in this study a shared Malaysian identity creates an opportunity for a new representation of Malaysian society in which new cultures of belonging re-emerge to chart a course towards a more just and unified society. Restructuring of Teachers preparation programme to address the increase of cultural diversity in Malaysia is vital. Modification of classroom instruction to respond positively to home culture of students is known in research literature as culturally compatible, culturally congruent, culturally responsive, and culturally relevant.

\section{Acknowledgements}

The author is grateful to IIUM for the support and funding provided in carrying out this research.

\section{References}

A. Samad Ismail. (1960). Ah Khaw Goes To Heaven. Berita Harian, 19.

Abu Samah, A. (2008). The development of English language policy in Malaysia: the new policy on science and mathematics in the medium of English ( $\mathrm{PhD}$ thesis, University of Sussex).

Ali, S. (1995). Teaching Literature in a Malaysian ESL context: Reflections and recommendations. English in Education, 29(1), 53-65.

Allwright, D. (1984b). The Importance of Interaction in Classroom Language Learning. Applied Linguistics, 5(2), 156-171.

Bhabha, H. (1994). The Location of Culture. New York, Routledge.

Braun, V., \& Clarke, V. (2006). Using thematic analysis in psychology. Qualitative Research in Psychology, 3(2), 77-101.

Brown, D. (2004). Urban teachers' professed classroom management strategies. Reflections of Culturally Responsive Teaching. Urban Education, 39(3), 266-289.

California Department of Education. (2009). English Language Arts Study Guide. CAHSEE.

Comber, L. (1983). 13 May 1969: A historical survey of Sino-Malay relations. Kuala Lumpur, Heinemann Asia.

Consolo, D. A. (2002). Teachers' action and student oral participation in classroom interaction. In J. K. Hall, \& L. S. Verplaetse (Eds.), Second and Foreign Language Learning through Classroom Interaction (pp. 91-107). Mahwah, N. J.: Lawrence Erlbaum.

Fearon, J. (1999). What is Identity (as we now use the word). Unpublished Manuscript. Stanford University.

Gay, G. (2000). Culturally responsive teaching: Theory, research, and practice. New York: Teachers College Press.

Gay, G. (2002). Preparing for Culturally Responsive Teaching. Journal of Teacher Education, 53(2), 106-116.

Giroux, H. (2001). Mis/Education and Zero Tolerance: Disposable Youth and the Politics of Domestic Militarization. Boundary 2, 28(3), 61-94.

Grbich, C. (2007). Qualitative data analysis: An Introduction. London: SAGE Publications Ltd.

Gutierrez, K., Baquedano-Lopez, P., Alvarez, H., \& Chiu, M. (1999). Building a culture of collaboration through hybrid language practices. Theory Into Practice, 38(2), 87-93.

Hall, S. (2003). Cultural Identity and Diaspora. In J. Rutherford (Ed.), Identity (vol. 36, pp. 222-237). Lawrence \& Wishart Ltd.

Herrigel, G. (1993). Identity and Institutions: The Social Construction of Trade Unions in the United States and Germany in the 19th Century. Studies in American Political Development.

Idrus, F. (2012). Shared Identity Construction: The Third Space Exploration. International Journal of Humanities and Social Science, 2(21). 
JanMohamed, A. R. (1985). The Economy of Manichean Allegory: The Function of Racial Difference in Colonialist Literature. Critical Inquiry, 12(1), 59-87.

Katzenstein, P. (Ed.). (1996). The Culture of National Security: Norms and Identity in World. Columbia University Press.

Ladson-Billings, G. (1994). The dreamkeepers: Successful teachers of African-American children. San Francisco: Jossey Bass.

Lee, S. K. (2003a). Multiple Identities in a Multicultural World: A Malaysian perspective. Journal of Language, Identity and Education, 2(3), 137-158.

Lee, S. K. et al. (2012). The English language and its impact on identities of Multilingual undergraduates. GEMA online Journal of Language Studies, 10(1).

Luke, C., \& Luke, A. (1999). Theorizing interracial families and hybrid identity: An Australian perspective. Educational Theory, 49(2), 223-249.

Ministry of Education Malaysia. (2004). The Development of Education. National Report of Malaysia.

Moll, L., Amanti, C., Neff, D., \& Gonzalez, N. (1992). Funds of Knowledge for Teaching: Using Qualitative approach to connect homes and classrooms. Theory into Practice, 31(2), 132-141.

Sampson, E. E. (1993). Celebrating the other. London: Harvester Wheatsheaf.

Shamsul, A. B. (1996). Debating about Identity in Malaysia: A Discourse Analysis. Southeast Asian Studies, 34(3), 476-499.

Singh, J. S., \& Mukherjee, H. (1993). Education and National Integration in Malaysia: Stocktaking Thirty Years after Independence. International Journal of Educational Development, 13(2), 89-102.

Tan, P. K. (2005). The medium-of-instruction debate in Malaysia. Language Problem \& Language Planning, 29(1), 47-66.

The New Malaysian Blueprint. (2012). http://www.moe.gov.my/usefiles/file/PPP/Preliminary-Blueprint-Eng.pdf

Wells, G. (2000). Dialogic inquiry in education: Building on Vygotsky's legacy. Invited presentation at NCTE, Detroit, November 1997. In C. D. Lee, \& P. Smagorinsky (Eds.), Vygotskian Perspectives on Literacy Research. Cambridge University Press.

Wendt, A. (1994). Collective Identity Formation and the International State. The American Political Science Review.

Wright, T. (1987). Roles of teachers and learners. Oxford: Oxford University Press.

\section{Copyrights}

Copyright for this article is retained by the author(s), with first publication rights granted to the journal.

This is an open-access article distributed under the terms and conditions of the Creative Commons Attribution license (http://creativecommons.org/licenses/by/3.0/). 